\title{
A Study on L2 Motivation and Applications in Reading Class in Senior High School
}

\author{
Zan Mao \\ English Department, Zhenjiang Watercraft College of PLA, Zhenjiang 212003, China \\ Email: shmaozan@sina.com
}

\begin{abstract}
Foreign language acquisition is a complicated process, which involved various factors. The personality factors, especially non-intelligence factors, such as motivation, attitude, character, etc. are the most direct and important ones. Among them, apparently, motivation is the key to learning. This thesis extends the previous studies, trying to have a basic understanding of Chinese senior high school students' reasons for learning English and their efforts paid in this learning process. This study was carried out among 96 students in grade 2 in Zhenjiang NO.1 middle school. A language learning motivation questionnaire was constructed based on Gardner (1985) to examine students' responses on 9 items. The results of the study show that students hold stronger instrumental reasons towards English learning, which is similar with the traditional view that instrumental motivation is more characteristic of EFL learners. However, instrumental motivation causes no effect on students' motivational intensity. The findings shed some lights on the teaching practice, especially on the reading class. One thing to emerge meaningfully from this study is that the combination of integrative motivation and instrumental motivation may exert a greater influence on reading class improvement; English teachers shall take some effective applications to arouse students' motivation in reading class and help them develop integrative motivation towards English learning.
\end{abstract}

Index Terms —instrumental motivation, integrative motivation, senior high school, reading

\section{INTRODUCTION}

Motivation, as a subjective factor, always affects students' learning behavior. Spolsky, an American linguist mentioned motivation as the combination of effort plus desire to achieve the goal of learning, plus favorable attitudes towards learning the language, could make a successful achievement in language learning (Spolsky, 1989). Lacking in desire or favorable attitudes, namely lacking in motivation, is one of the most important factors that hinder Chinese senior high school students' progress in reading class.

The role of motivation in language learning has been studied since 1960s. Most language teachers will agree that motivation of the students is one of the most important factors influencing their success or failure in language learning. American linguist Brown said that if one has the proper motivation in second language learning, he could certainly be successful (1994), which bought out the importance of motivation and the way it can overcome unfavorable circumstances in other aspects of language learning.

From the second half of the twentieth century, researchers have begun to analyze child language learning systematically. They have attempted to discover the nature of the psycholinguistic process that enables every human being to gain great control of an exceedingly complex system of communication (Sun Lei, 2005). Linguists have divided motivation into many types, such as integrative / instrumental motivation ---- put forward by Wilkins (1976), Gardner and Lambert (1972), or intrinsic / extrinsic motivation ---- defined by Deci Edward (1975) and Brown (1994). Linguists like Ball (1957), Bruner (1966), Hunt (1965) and Schmidt (2001) also made great contribution to the development of motivation research.

The present thesis addresses some of the above issue by an empirical study investigating a sample of 96 Chinese senior high school students from Zhenjiang NO.1 middle school. Based on a partly self-made questionnaire concerning their motivation in language learning, this study intends to have a basic understanding of students' reasons of English learning and give some suggestions to their English reading class.

The structure of the thesis is as follows. It begins with a brief review of research in the theory of motivation and the classification of motivation types, laying a solid foundation for the theoretical background of the present thesis. Chapter 3 is concerned with the research design of the survey study, which introduces the subjects of the study, the instruments employed to measure students' motivation, and the analytical methods to be adopted. In the next chapter, Chapter 4 , the research results is given, and some suggestions are also put forward as the effective ways which can be applied in reading class. It is the main section of the thesis and closely related to the factors that mentioned in Chapter 3 . The .final chapter is to summarize the major findings of the study, and will also pinpoint the limitations inherent in this study and make some suggestions for further research.

\section{LITERATURE REVIEW}




\section{A. Theories of Motivation}

What is motivation? Motivation is a rather internal drive and emotional effect that encourages people to pursue a course of action (Wang Xianjie, 1999). Spolsky said, "The more motivation a learner has, the more time he or she will spend learning an aspect of a second language.”(Wang Xianjie, 1999, cited in Spolsky, 1989).

Ball (1957) claimed that motivation is the most important concept in any theory of education. Therefore, it is essential to demonstrate different points of view on definitions of motivation in order to achieve a better understanding of the role of motivation in language learning. According to Ball, motivated students refer to those who wish to do things that teachers expect, while unmotivated students are the ones who are unwilling to do things based on teachers' expectation. In contrast with teachers, psychologists (Lewin, 1952) study the concept of motivation to a greater extent. Lewin emphasizes that learning itself is motivation, which determines success. However, Bruner (1966) seems not to be in line with this suggestion, arguing that when learners are forced or pushed to learn, they might fail to maintain their natural curiosity. In contrast, Beard and Senior (1980), two behaviorist psychologists, believe that "incentives and rewards" are motivations for establishing behavior. Spencer (1959) appears to support this idea, suggesting that it is primarily important for teachers to apply various types of "rewards" to stimulate students to possess "interest and goals" in the performance of tasks.

The best-known and frequently quoted definition of L2 learning motivation is Gardner's. According to Gardner (1985, p.10), motivation is "the extent to which an individual works or strivers to learn the language in this activity." Gardner and MacIntyre (1993, p.2) express this again 8 years later, in a simpler way as "motivation is defined by three components: the desire of achieving a goal, the effort extended in this direction, and the satisfaction with the task." On a basis of these conceptions, many language researchers have contributed themselves to the study of the role of motivation in language learning.

Williams, M. \& Burden, R (1997, p.6) defined the motivation as: "Motivation may be constructed as a state of cognitive and emotional arousal, which leads to a conscious decision to act, and which gives to a period of sustained intellectual and/or physical effort order to attain a previously set goals." This definition involves three stages: 1. The initial stage: whatever the cause, the individual's interest or enthusiasm is aroused; 2 . The decision-making stage: the individual consciously decided what action to take; 3 . The effort-sustaining stage: once the activity has begun, the individual needs to persist until the desired goal is achieved.

As illustrated above, definitions of motivation can be given from different ways of thinking. In the next section, the role of different types of motivation occurring in current research will be examined.

\section{B. Classification of Motivation Types}

Closely related with the definition problem, is the way motivation is classified. There are 2 major classifications about motivation: integrative / instrumental; intrinsic / extrinsic.

1. Integrative / instrumental motivation.

What is the most impressive in Gardner's traditional research is the famous classification of integrative and instrumental L2 motivation. When learning a target language, some students like the people who speak the language, admire the culture and have a desire to become familiar with or even integrate into the society in which the language is used. This form of motivation is known as integrative motivation. Integrative motivation indicates an interest in learning a foreign language to communicate with members of the foreign language community (Gardner, 1985). This motivation occurs when the learners wish to understand the culture of the foreign language.

In contrast to integrative motivation is the form of motivation referred to as instrumental motivation. Instrumental motivation means learning the language for an ulterior motive unrelated to its use by native speakers (Gardner, 1985). It stresses on the pragmatic aspects of learning a language without particular need of communication with the foreign language community. Wilkins said that the instrumentally motivating learner requires the language as a means to some other end, whereas for the integrative learner the language and all that it brings by way of culture is an end in itself (Wilkins, 1976).

Both integrative and instrumental motivations are essential elements of success, integrative motivation may be a profound one and the other is somewhat superficial. It is integrative motivation that has been found to sustain long-term success when learning a second language. In some of the early research conducted by Gardner and Lambert (1972), integrative motivation was viewed as being of more important in a formal learning environment than instrumental motivation. In later studies, integrative motivation has continued to be emphasized, although now the importance of instrumental motivation is also stressed. It may be that integrative motivation is more important in a second language context such as learning French in Canada, while an instrumental orientation may be more important in situation where English functions as a foreign language such as in Japan (Guo Limin \& Zhai Shijun, 2000, cited in Niitsuma, 1992).

2. Intrinsic / extrinsic motivation.

In education psychology a distinction is usually made between intrinsic and extrinsic motivation, the former being sometimes thought to relate to long-term success. Intrinsic motivation is usually defined as a motivation guided by an interesting in the task itself in which one is engaged. Edward Deci (1975) defines intrinsic motivation as one for which there is no apparent reward except the activity itself. People seem to engage in the activities for their own sake and not because they lead to an extrinsic reward. Intrinsically motivation behaviors are aimed at bringing out certain internally 
rewarding consequences, namely, feeling of competence and self-determination.

On the other hand, extrinsically motivated behaviors are carried out in anticipation of a reward from outside and beyond the self. It is said be guided by external stimulus, such as to get the parental approval, a reward, a good grade, etc. Behaviors initiated to avoid punishment are also extrinsically motivated.

The relationship between intrinsic motivation and extrinsic motivation is just like that between internal and external causes. Materialist dialectics holds that external causes become operative through internal causes. Traditionally, schools were fraught with extrinsically motivation behavior, influenced by behaviorism. Teaching material, parents and teachers' wishes are all forced onto students, whether they like them or not. Consequently, the students are not taught to develop internalized thirst for knowledge and experience (Brown, 1994). From extrinsic to intrinsic motivation in education institutions depicts what can happen in an institution and turns the extrinsic pressure into an intrinsically oriented direction.

\section{RESEARCH METHODOLOGY}

As is mentioned in chapter 2, many researchers at home and abroad have done a lot of related researches on both motivation and motivation stimulating. With the economic development, China has become a much more open country than ever before, so English, which is a global language, has become a very important means by which Chinese people learn about the world and the indispensable means to communicate with foreigners. Have the students in senior high school realized the importance of English? Do they know quite well about their purpose of learning English? Which ways can stimulate their motivation on learning English? In order to find answers to these questions, the questionnaire was designed. Moreover, study process and results discussion will also be given.

\section{A. Subjects}

The subjects for this study consisted of 96 students at Zhenjiang NO.1 middle school, including 42 males and 54 females whose average age at 17.8 years old. They were chose at random from 3 classes in grade 2 in this senior high school.

\section{B. Instruments}

A questionnaire was used as the instrument in this study. It consisted of two parts (see appendix). The first part was concerned with personal information, such as the participant's name, class.

The second part of the questionnaire measured the type of English learning motivation. Statements in this section were mostly adapted from the published motivation scales of language learning: the Attitude/Motivation Test Battery (Gardner 1985). Because this scale did not contain statements relevant to Chinese students learning motivation, some newly designed questions were added. The participants were asked to rate each item on a five-point Liker scale: $1=$ never or almost never true of me; $2=$ generally not true of me; $3=$ somewhat true of me; $4=$ generally true of me and $5=$ always or almost always true of me.

9 items were selected to find out students' language study for integrativeness or instrumentality. Items $2,3,5,7$ were for revealing students' integrative motivation and all the items in this factor had the salient trait of internal appreciation of culture in another country and enjoyment of learning the language. Items 1, 4, 6, 8, 9 were for instrumental, which indicated learning a foreign language as a tool to fulfill goals. The total score of the questionnaire was 45 , with integrative motivation 20 and instrumental motivation 25 . The higher score the respondent got in integrative or instrumental motivation subscale, the more integratively or instrumentally motivated he was.

\section{Procedures}

The questionnaire was completed during regular class sessions in December. Under their English teacher's supervision, students were asked to give their immediate reaction to questions as accurately as possible. Time spent for the completion did not exceed 5 minutes. The purpose of the questionnaire, its structure and content, and how it was to be filled out were explained to the students. The researchers asked the participants to be honest in their answers and emphasized that they had no predetermined expectations and that no answer would be better than the respondents' true ideas. No communication was permitted before students completed the questionnaire. After the questionnaire was finished, the researcher collected all the paper and checked them one by one to avoid any missing response.

After all the data were collected, they were sorted and processed in the computer. Descriptive statistics was used to reveal the general characteristics of instrumental motivation, integrative motivation and motivational intensity possessed by senior high school students.

\section{RESUlTS DisCUSSION AND APPLICATIONS}

\section{A. Descriptive Statistics of the Type of Motivation and Motivational Intensity}

As can be seen in Table 4.1, there were a substantial number of significant difference involving the two kinds of motivation. Students showed a stronger tendency toward instrumental motivation than integrative motivation, with mean score of instrumental 15.7000 and that of integrative 11.1474 and the difference was significant at the level of .000. Correlation coefficient at .053 showed the items in the respective category of instrumental and integrative were 
well defined. There was nearly no overlap between the two types of motivation, for the correlation was very low. This accords with the view expressed by Kruidenier and Clement (1986) that instrumental motivation was generally more prominent in EFL contexts than integrative motivation. Even though many studies have proved the fact that integrative motivation is the main factor that influences students' learning behavior, those studies are nevertheless conducted in the learning context where English is learnt as the second language. Ellis (1994) restated that the factor of social situation helps to determine both what kind of orientation learners have and what kind is most important for language learning. Students' instrumental dominance in this study may stem from the Chinese social environment for language learning. It seems that being a knowledgeable person is the honor of a family. And Chinese youngsters have the tradition to obey their parents' will. Most of the senior high school students are urged to study hard in order to live up to their parents' expectations. Another main reason of students' instrumental orientation is that English becomes a fundamental subject due to the opening-up and reform policy which opened the door of China to foreign countries. Speaking Chinese alone is not enough to ensure a full and productive participation in foreign trade and international communication. With the increasing importance attached to English, all kinds of English level tests were established to test students' proficiency. Against this background, the centrality of instrumental motivation among Chinese senior high school students becomes quite understandable.

TABLE 4.1:

DESCRIPTIVE STATISTICS OF THE TYPE OF MOTIVATION AND MOTIVATIONAL INTENSITY

\begin{tabular}{|l|l|l|l|l|l|}
\hline DESCRIPTIVE STATISTICS OF THE TYPE OF MOTIVATION AND MOTIVATIONAL INTENSITY \\
\hline & Mean & $\mathrm{N}$ & Std. Deviation & correlation & sig \\
\hline $\begin{array}{l}\text { Instrumental } \\
\text { (item } 1,4,6,8,9)\end{array}$ & 15.7000 & 96 & 3.1420 & .053 & .000 \\
\hline $\begin{array}{l}\text { Integrative } \\
\text { (item 2,3,5,7) }\end{array}$ & 11.1474 & 96 & 3.0113 & & \\
\hline
\end{tabular}

\section{B. Suggestions in English Reading Class}

The real good of any theory lies in its guidance to practice. This is especially true with motivation theories whose researches have always been hand in hand with the study of human learning and language learning, in particular. Since 1990s, motivation study has been currently directed to serve educational purposes. However, the research in the area of designing motivational strategies for classroom application is far from adequate. As foreign language teachers, we are most concerned with how we can intervene. Namely, what we can do to motivate learners. This chapter will pay special attention on five aspects of how to maintain senior high school students' interest and motivation in English reading.

1. Arousing learners' curiosity

To make a lesson lively and interesting, the teacher may create a real-life situation and speak as much English as possible in class. However the method by which the students are taught must have effect on their motivation and interest. If they find it deadly boring they will probably become abstracted whereas if they have confidence in the method, they will be interested greatly, consequently it is necessary to demand the teacher to use various activities to achieve the goal.

a. Use multi-media technologies

The application of multi-media technologies in the 21 st century has brought forth opportunities and challenges to foreign language education. Since students in senior high school have their particular mental features, they have sociality and irritability in common which means that they are usually easier to be attracted by fangless, more active to issue their opinions about surroundings, and more yearning to participate in the social life. Their thought developed acuminous but unilateral and extreme; their emotion become intense and always wavy; they have a high curiosity on the unknown world study but easy to distract from the object so that they need various stimulators to excite all their sense organ including eyes, ears, mouths and even noses to keep their interest (Ni Lingjie, 2006). Traditional teaching aids, such as chalk and blackboard, cannot be competent for holding students' interest persistently. It is of great necessity that we develop English teaching models in the teaching-learning environment supported by modern technology. The application of computer-assisted instruction, like multi-media technologies, should play a more and more important role in the English class.

Take Lesson35 Animals in Danger in SEFC BOOK II for example, teacher could begin the class with a film editing displays the virgin forest in where a lot of various animals live to attract students' interest immediately, then suddenly switch into the scene that dead whale on the foreshore and a group of running deer capturing by humans. The title of the text----Animals in Danger then jumps out. Students can easily comprehend the theme of that lesson imminently.

This is a good method which create abundant language situation, increase class capacity, raise teaching efficiency, enrich teaching resources, and all the points above can stimulate students' interest.

b. Use various methods

Various teaching methods should be run through the whole reading class. There are several efficient activities could be taken through pre-reading, while-reading to post-reading as following:

1) prediction:

There are many good methods for arousing learners' curiosity in pre-reading period, and prediction is one of them. The reader's sense and experience will help him to predict what the writer is likely to say next. A reader who can go 
along with the writer's thought in this way will understand the text more quickly. This often occurs but unconsciously. As we read we make hypotheses about what the writer intends to say, these are immediately modified by what he actually does say, and are replaced by new hypotheses about what will follow. We carry on reading like that until suddenly we are brought to a stop by some word or phrase we don't understand or would not fit into the pattern. We have to do something about it and think again. So reading comprehension is a process of constantly making hypotheses or prediction (Sun Yibing, 1995). This is a useful skill in reading. Each time before we start reading we should try to encourage the students to ask some questions on the title, the content of the text, etc., in order to help the students learn to predict.

2) quizzes:

Teacher can use interesting quizzes to have the students practice specific language points acquired from the reading text in while-reading period. This activity can be put up like the model that follows:

Divide students into two groups. Give each group some time to write down a number of questions using the specific language items to be practiced. Then a student from Group A asks a question to a student from Group B. The teacher may mark their questioning and answering. This activity can be quite efficient in cultivating the students' interest and motivation.

3) proper correction:

During the course of any activity the students do in while-reading, they will probably make some errors. However the teacher need not always correct them each time unavoidably, because too much correction will discourage students and they will be reluctant to take part in the activity in fear of making mistakes. The object of correction is to give the students a chance to find their weakness in study and get the new language right by themselves so that their motivation could be aroused.

For example, a teacher could simply indicate to the student that he has made a mistake, by repeating, stressing, questioning or making expressions. The teacher could ask the students, "Is that sentence right?" If the student understands this feedback, he will be able to correct it himself, and this self-correction, will be helpful to him as part of his learning. If the student fails to correct himself, the teacher may ask another student to help him to correct.

It is often the case that the teacher asks for student-student correction only to find that many students are having the same mistakes, and then the teacher may correct them himself, and return to the explanation to make the paint clear.

4) role-play:

Role-play can be used in arousing students' motivation in post-reading. In this activity the teacher may ask the students to re-play the text by their own words or phrases. It has at least two purposes: first, to test if the students understand the main idea of the text; second, to vivid the classroom and persist the interest in the post-reading stage.

Take the text "The Lost Necklace" from SEFC BOOK II for example, the teacher may ask one student to play the part of Mathilde, another the role of Jeanne, and then the play may begin. Or the teacher asks some students to pretend that they are at a bookshop to play the roles of customers and shop assistant. All that the teacher is trying to do is giving the students practice in real-world English. In both of these two cases the teacher is asking some students to play roles while others are taking part in a simulation as themselves. And to do this, they all need to do a certain amount of "acting" and this means they have entered the activity with enthusiasm and conviction.

2. Identifying learners' Personal Needs

In view of Chinese students' specific background, they tried to identify students' needs and planed lessons on the ground that they must create an atmosphere in which all students felt the need of continuing to learn English.

Only when the teachers let them learn English for their own future purposes can they learn it actively. (Wang Zanjie, 1994) Thus the English teacher should make full use of their enthusiasm to lead them to efficient English learning and should not make them bear in mind the only reason of learning English, which is to pass the entrance examinations. In this way they can be steady and motivated, and they would like to smooth away the difficulties and find that English learning is not so hard because they have a pursuit of fulfilling their wishes, which drives them to carry out the action of learning the language.

3. Cultivating students' language competence

Many things are involved in cultivating students' language competence. The goal of a reading course is realized through reading activities. The stress of teaching should be placed on the reading process rather than students' grades. Teaching should aim at making students feel that they still need to learn, and they will learn a lot; that they are capable of learning, communicating with English speakers and thinking in English. In short, they are experiencing the joy as well as the value of reading in English so that their motivation in reading would be aroused. For this reason, teachers should help students to cultivate their language competence in several main points as follows.

a. Build up the vocabulary

One with a small vocabulary will find it very difficult in reading comprehension. Many students say they just cannot remember so many words. For encourage students enlarge their vocabulary more self-conscious and motivated, we should take some techniques:

1) learn about word formation:

Students can enlarge their vocabulary by using the rules of word formation, such as prefix, suffix, conversion, derivative and so on. 
For example, if students know the prefix "inter-"means between, they will feel easy to understand the word "intercourse" (communicating between), "interpret" (translating between), and "interact" (acting between). When students know the suffix "-ial"means characteristic of doing, they could understand the word "beneficial"(characteristic of doing good), "facial"'(characteristic of doing something about face), "referential"(characteristic of referring). The same case can be found in the mastery of derivatives, once they knows the word "courage", "encourage, discourage, courageous" will not be new to them.

Students could identify the word they willing to know by using the rule of word formation so that they may be more active in English study and more interested in language learning.

2) encourage students to guess the word's meaning:

Teacher can collect some new words that students often meet in reading. This doesn't mean encouraging them to consult the dictionary whenever they met a new word in reading. The appropriate way is to try to guess the word's meaning from context clues, from the words around it, and then they will gradually know the clear meaning of the word after meeting it often. After that, if they look it up in the dictionary, they will have a good memory of it.

3) learn the frequently used words every day:

Young students have good memories. It is possible for them to memorize some words every day without much difficulty. But if they can't use them in daily life, they will forget them quickly. In order to avoid the inefficient words acquirement, the teacher may choose some useful and frequently used words for them, and encourage them use them as many as possible in their daily life. When students meet these words in their reading, they will feel easy and more confident with themselves, which can make them become more interested in reading.

b. Develop broad background knowledge

To become a good reader, one should also read often and read a lot. And to learn about English culture will be of great help, too. When readers have sufficient knowledge of a given text and language, they may discover their own strategies to understand the meaning of text.

The background knowledge can be broadened by reading newspapers, magazines, and books; become interested in world events. Teacher can also select some correlative and particular materials for them to develop students' background knowledge.

4. Choosing interesting materials

The choosing of reading materials is very important for effective teaching of a reading course, because reading materials directly affect students' reading interest and their motivation. Sometimes, teacher in senior high school may use as more as possible interesting materials especially written for extensive reading, because most of the textbook are abridged and therefore are not authentic in the sense of originality. We should provide them with suitable texts, such as texts in science and technology, literature, advertisements, business letter, charts, instructions or directories, etc. from simplified to authentic. The texts should be interesting and it would be better if there lays the concern of students.

Students in senior high school at 16 to 19 years old, are always interested in the reading materials whose contents are about students' life inside and outside school, house life, weather, festivals, health and so on (Duan Bixi, 2001). Therefore, as chapter 3 has mentioned, if talking about computer, it is better to provide them the article about what amazing work can a computer does rather than what is a computer made of.

There also should not be too many new words in these articles. As for extensive reading the average new word percentage is approximately 3\% to 6\%. (Sun Yibing, 1995) In this way the students' motivation for reading can be stimulated.

Besides choose more interesting materials, teacher may also introduce some global issues to activate students' interest in reading, and even conduct some classroom discussions about global issues as the post-reading activity.

It is important for the teacher to take advantage of such discussion topics and help students to realize that, even though they may see no need to become proficient in a second language, the study of another language and culture can only enhance their perception and understanding of other cultures.

5. Teacher's role in motivating students

In teaching reading, a teacher is not expected to teach language only. His major aim is to help the students learn how to get rid of the obstacles in their way of comprehension and how to read effectively and also learn how to use the language.

It is easy for the teacher to give too much help, or help of the wrong kind. We should not provide so much help that it becomes a crutch the students cannot do without. The help we offer can only serve as a baby's walking-chair, which they can rely on for merely a short period of time, not all their lives.

According to Chinese researcher Song Yuelan (2002, p.49), a good teacher usually has the main qualities, which help providing students' intrinsic motivation as follows:

a. Makes his course interesting;

b. Has good pronunciation;

c. Explains clearly with simple English;

d. Shows same interest in every student;

e. Makes students participate;

f. Shows great patience; 
g. Shows sympathy for his students;

h. Inspires confidence.

Apart from the qualities above mentioned, a good teacher must be able to show his acquaintance of his subject.

There are many different factors that affect a student's motivation. Above all, both positively motivated students and those who don't have this motivation can be influenced by what happens in the classroom. Thus, the attitude toward English of those around the students and the teacher's personality are vital important for them to get motivated. And students who are frequently praised or positively commented will result in greater success.

To draw a conclusion, no matter what the underlying motivation to study a second language, what cannot be disputed is the fact that motivation is an important variable when examining successful second language acquisition. Although change may be slow to the education system, the introduction of the English language as a subject in senior high school should always help to further motivate students to achieve higher levels of proficiency in the future.

\section{CONCLUSION}

\section{A. Major Findings in This Study}

How people learn and what is learning have been the focus of educators, theorists, researchers and others for a long time. Understanding the learner and how learning takes place for that individual is the key to know how to teach that individual. We know motivation has greatly influenced a learners' second language learning, especially in reading case. And it is absolutely true that some L2 learners do better in reading class than others because they are better motivated. The usual meaning of motivation for the teacher is probably the interest that something generated in the students. L2 motivation should not be considered as a forced choice between the integrative and the instrumental. Both types are important. A student might learn a L2 well with an integrative motivation or with an instrumental one, or indeed with both, for one does not rule out the other, or with other motivations.

Nevertheless students will find it difficult to learn a second language in the classroom if they have neither instrumental nor integrative motivation, as is probably often the case in school language teaching. Schoolchildren have no particular contact with the foreign culture and no particular interest in it, nor do their job prospects depend on it. A problem teachers facing is that motivations for L2 learning are deep- rooted in the students' minds and in their cultural backgrounds. The general issue is how the students' cultural background fits the background projected by the L2 culture. Students should enter the classrooms admiring the target culture and language, wanting to get something out of the L2 learning for themselves, and thirsting for knowledge. In practice teachers have to be aware of the reservations and preconceptions of their students. What they think of the teacher, and what they think of the course, heavily affects their success. This is what teachers can influence rather than the learners' more deep-seated motivations. Motivation also goes in both directions. High motivation is one factor that causes successful learning; successful learning, however, may cause high motivation. The latter process of creating successful learning, which can spur high motivation, may be under the teacher's control, if not the former. The choice of teaching materials and the information content of the lesson, for example, should correspond to the motivations of the students.

In order to make the language learning process a more motivating experience, teachers need to put a great deal of thoughts into developing programs which maintain student interest and have obtainable short term goals. English teachers in senior high school need to create interesting reading lessons in which the students' attention is gained. This can sometimes be accomplished by the use of teaching strategies, which are not often called upon by other teachers in mainstream subject areas. Encouraging students to overcome more active participants in a lesson can sometimes assist them to see a purpose for improving their communication skills in the target language. Successful communication using the target language should result in students feeling some sense of accomplishment. Research in the area suggests L2 achievement strongly affects learner motivation.

The use of an interesting text can also help to increase the motivation level of students in the reading classroom. It is important for the teacher to take advantage of such discussion topics and help students to realize that, even though they may see no need to become proficient in a second language, the study of another language and culture can only enhance their perception and understanding of other culture.

Although statistics in Chapter 3 showed that Chinese students have a stronger tendency toward instrumental motivation than integrative motivation, the integrative motivation and instrumental motivation should play an equal indispensable part in L2 reading learning. Language learners and teachers should take advantage of the positive role of the motivation to attain the end that is to learn and teach L2 reading efficiently. No matter what the underlying motivation to study a second language, what cannot be disputed is the fact that motivation is an important variable when examining successful second language acquisition. It cannot be denied that there are some more or less problems in our language learning and teaching system, and change may be slow to the education system. Students and teachers in senior high school should overcome the present difficulties to achieve higher level of proficiency.

\section{B. Limitations in This Study}

Though this study has successfully investigated Chinese senior high school students' motivation in English learning, it has some limitations, which provide some insights for the future study. The first limitation is the subjects in the study. Since the results of the present study are drawn 96 students whom com from the same school, the ability to generalize 
its findings to all students may be restricted. The second limitation is the questionnaire. Since time was limited, the questionnaire was too simply designed that some researchers will have doubts on its reliability and validity. Future studies call for continuous efforts to improve the questionnaire. This study, on the whole, is an integral part of motivation research and will bring more researchers to plough this field.

\section{APPENDix LANGUAGE LEARNing Motivation QueSTIONNAIRE}

外语学习动机调查问卷

姓名: 班级:

本问卷旨在调查高中生英语学习动机的有关情况。学生所选取的任何答案都无对错之分, 更不会记入成绩。 请根据自己的实际情况，按照数字“1”，“2”，“3”，“4”，“5”所代表的含义，如实地选出其中最符合自己情况的 一项。谢谢合作!

1: 这完全不符合我的情况

2: 这通常不符合我的情况

3: 这有时符合我的情况

4: 这通常符合我的情况

5：这完全符合我的情况

外语学习动机:

1. 我学习英语是为了通过考试

2. 我学习英语是为了更轻松地与外国人交流

$\begin{array}{lllll}1 & 2 & 3 & 4 & 5\end{array}$

3. 我学习英语是因为对英语国家的人以及他们的生活方式感兴趣 $1 \begin{array}{lllll}1 & 2 & 3 & 4 & 5\end{array}$

4. 我学习英语是为了不幸负父母的期望 $\quad 1 \quad 2 \quad 3 \quad 4 \quad 5$

5. 我学习英语是为了能更自如地参与英美文化团体的活动 $\begin{array}{lllll}1 & 2 & 3 & 4 & 5\end{array}$

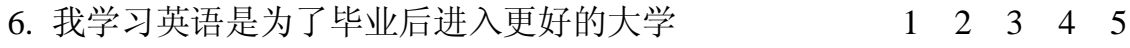

7. 我学习英语是为了更好地欣赏外国的文学作品和音乐 $\begin{array}{lllll}1 & 2 & 3 & 4 & 5\end{array}$

8. 我学习英语是为了出国 $1 \begin{array}{lllll}1 & 2 & 3 & 4 & 5\end{array}$

9. 我学习英语是因为说英语是教育程度和修养的象征 $\quad \begin{array}{lllll}1 & 2 & 3 & 4 & 5\end{array}$

\section{REFERENCES}

[1] Ball, S. (1957). Motivation in Education Academic. New York, San Francisco, London: Academic Press.

[2] Bruner, J. S. (1966). Toward a Theory of Instruction. New York: Norton.

[3] Beard, R. M., and Senior, I. J. (1980). Motivation Students. London: Routledge and Kegan Paul.

[4] Brown H. Douglas. (1994). Teaching by Principles. New Jersey: Prentice Hall Regents Prentice-Hall, Inc.

[5] Deci, Edward L. (1975). Intrinsic Motivation. NY: Plenum Press.

[6] Ellis, R. (1994). The study of second language acquisition. Oxford, England: Oxford University Press.

[7] Gardner, R.C. and Lambert, Wallace, E. (1972). Attitudes and Motivation in Second Language Learning. Rowley MA: Newbury House. 138

[8] Gardner, R.C. (1985). Social Psychology and Second Language Learning: the role of attitudes and motivation. London: Adward Arnold.

[9] Gardner, R.C. and MacIntyre, P. D. (1993). A student's contributions to second-language learning. Part II : Affective variables. Language Teaching, 26, 1-11.

[10] Hunt, J. McV. (1965). Intrinsic Motivation and its Role in Psychological Development. In D. Levine (Ed) Nebrask Symposium on Motivation, Vol. 3. Lincoln: University of Nebrask Press.

[11] Kruidenier, B., and Clement, R. (1986). The effect of context on the composition and the role of orientations in second language acquisition. Quebec City: International Center for Research on Bilingualism.

[12] Lewin, K. (1952). Field Theory in Social Science. Selected Theoretical Papers. New York: Tarvistock.

[13] Spencer, K. W. (1959). The Relation of Learning Theory to The Technique of Education. Educational Review. $29,84-95$.

[14] Spolsky, B. (1989). Conditions for Second Language Learning. Oxford: Oxford University Press.

[15] Schmidt, R. (2001). Attention. In Robinson, P. (ed.). Cognition and Second Language Instruction. NY: Cambridge University Press.

[16] Wilkins, D.A. (1976). National Syllabuses. Oxford: Oxford University Press.

[17] Williams, M. \& Burden, R., (1997). Psychology for Language Teachers. Cambridge, UK: Cambridge University Press.

[18] Duan Bixi. (2001). Developing Students' Reading Abilities in Junior School. Journal of Baoshan Teachers College, 20 (3):86.

[19] Guo Limin \& Zhai Shijun. (2000). Motivation-Theories and Beyond. Journal of Capital Normal University, Supplement: $87-92$.

[20] Song Yuelan. (2002). Motivation for English Learning. Journal of Weinan Normal University, 7: 49.

[21] Sun Lei. (2005). Motivation in Second Language Learning and English Teaching. Journal of Jilin Engineering Teachers College, 21(8): 48.

[22] Wang Zanjie. (1994). Cultivation of Students' Interest and Motivation in The English Language Learning. Journal of Xingtai Teachers College, 3: 13. 
[23] Wang Xianjie. (1999). Motivation---- A Factor Affecting Foreign Language Learning. Journal of Henan Institute of Education, 1(67): 72-73.

[24] Ni Lingjie. (2006). Mentality Characteristic of Students in Senior High School \& Politics Class Teaching. Journal of Mudanjiang Institute of Education, 2(96): 64-67.

[25] Sun Yibing. (1995). Guidance in Effective Reading. Journal of Tianjin Foreign Language University, 1: 28-30.

Zan Mao was born in Zhenjiang, China in 1985. She received her B.A. degree in Foreign Linguistics from Shanghai Normal University, China in 2007.

She is currently an assistant in English Department, Zhenjiang Watercraft College of PLA, Zhenjiang, China. Her research interests include Second Language Acquisition and Foreign Language Teaching. 